\title{
Isotherm, Kinetic and Thermodynamic Studies for the Sorption of Mercury (II) onto Activated Carbon from Rosmarinus officinalis Leaves
}

\author{
Mohamed Erhayem1, Fatima Al-Tohami', Ragwan Mohamed ${ }^{2}$, Khadija Ahmida' \\ ${ }^{1}$ Department of Chemistry, Faculty of Science, Sebha University, Sebha, Libya \\ ${ }^{2}$ Department of Chemistry, Faculty of Science, Sirte University, Sirte, Libya \\ Email: irhim2002@yahoo.co.uk
}

Received 2 October 2014; revised 16 November 2014; accepted 3 December 2014

Copyright (C) 2015 by authors and Scientific Research Publishing Inc.

This work is licensed under the Creative Commons Attribution International License (CC BY).

http://creativecommons.org/licenses/by/4.0/

(c) (i) Open Access

\begin{abstract}
The present work deals with the equilibrium adsorption of $\mathrm{Hg}(\mathrm{II})$ onto carbonized Rosmarinus officinalis leaves (ACROL) as a new adsorbent from aqueous solution and it has been investigated. ACROL samples were prepared by physical carbonization at $773 \mathrm{~K}$ for $1 \mathrm{~h}$. Titration method was used to determine the concentration of $\mathrm{Hg}$ (II) before and after adsorption onto ACROL by ethylenediaminetetraacetic acid, EDTA, as chelating agent. Batch equilibrium studies were carried out under different experimental conditions such as $\mathrm{Hg}$ (II) concentration and temperature. The relationship between the amount of $\mathrm{Hg}$ (II) onto ACROL can be described using four tow-parameter isotherm models. The equilibrium sorption data were analyzed using Freundlich, Langmuir, Dubinin-Ra- dushkevich (DRK) and Temkin isotherms. The experimental results were found to fit the Langmuir isotherm model with a monolayer adsorption capacity of $588.2 \mathrm{mg} / \mathrm{g}$ at $318 \mathrm{~K}$, while they were found to fit the Freundlich isotherm model at $298 \mathrm{~K}$. The $K_{L}$ was decreased with increasing temperature, indicating a bond strength between $\mathrm{Hg}(\mathrm{II})$ and ACROL decreased with increasing temperature and sorption is exothermic. From DRK isotherm, free energy, $E$, was higher than $31 \mathrm{~kJ} / \mathrm{mol}$ suggesting the $\mathrm{Hg}$ (II) adsorption onto ACROL chemical sorption. The thermodynamic studies revealed that the process is spontaneous nature of $\mathrm{Hg}$ (II) adsorption by ACROL and exothermic. The findings from this research show that ACROL has capability to remove $\mathrm{Hg}$ (II) from aqueous solutions.
\end{abstract}

Keywords

Adsorption, Hg(II), Isotherm, Kinetic, Thermodynamic, Rosmarinus officinalis Leaves

How to cite this paper: Erhayem, M., Al-Tohami, F., Mohamed, R. and Ahmida, K. (2015) Isotherm, Kinetic and Thermodynamic Studies for the Sorption of Mercury (II) onto Activated Carbon from Rosmarinus officinalis Leaves. American Journal of Analytical Chemistry, 6, 1-10. http://dx.doi.org/10.4236/ajac.2015.61001 


\section{Introduction}

The removal of heavy metals released from industrial water into environments is a matter of great interest due to their toxicity and industrial activities in large amount of non-degradable heavy metals [1]. In 1999, 48 tons of mercury was emitted globally into atmosphere from coal-fire power plants in US [2] [3]. $\mathrm{Hg}$ (II) is water-soluble in water and can be converted to methylmercury in the presence of micro-organisms, which is a highly toxic form [4]. Mercury metal can be transported over long distance and may be bio-accumulated in the food chain like fish and interfere with ozone depletion in the arctic [3]. Increased applications of Hg(II) have led to increase in possible risks to the environment, so the removal of $\mathrm{Hg}(\mathrm{II})$ becomes crucial.

The treatment of waste waters from $\mathrm{Hg}(\mathrm{II})$ is one of the growing needs in environmental applications. However, several processes are useful to remove these heavy metals from water and wastewater including chemical precipitations, ion exchange, membrane filtration, adsorption flotation, and coagulation flocculation [5] [6]. Adsorption is one of the most widely used methods for removal of heavy metals from waste waters due to low-cost sorbent and eco-environmental materials [7]. Several adsorbents have been used to remove the heavy metals from waste waters such as olive stones, palm kernel oil, pumpkin seeds, melon seeds etc. [8]-[10]. Rosmarinus officinalis Leaves (ACROL) is used as a decorative plant in gardens and many medical uses [11]. Also, ACROL are used to flavor foods such as roast meats [11]. Due to the natural abundance in the environment and cheap especially in Libya, ACROL can be applied for heavy metal removal from aqueous solution. Also, in our previous work, we reported that the ACROL could remove Hg(II) from aqueous solution; in which the adsorption capacity depended on agitation time (75 min), $\mathrm{pH}$ of 2.4 and dosage of ACROL [12]. The aims of this research are to investigate the possibility of using ACROL as efficient alternative adsorbent materials to remove $\mathrm{Hg}$ (II) from aqueous solution using different isotherm models and to evaluate thermodynamic and kinetic of Hg(II) adsorption onto ACROL.

\section{Materials and Methods}

\subsection{Chemicals and Instruments}

All the chemicals used in this work were purchased from Merck, Germany and BDH, England and used without further purifications. The stock solution of $\mathrm{Hg}$ (II) was prepared by dissolving mercury acetate in distilled water and the desirable concentrations of $\mathrm{Hg}(\mathrm{II})$ were obtained by diluting the stock solution, in 100 - $400 \mathrm{mg} / \mathrm{L} \mathrm{range}$. The solution pH was measured by pH Jenway 3505 Model and adjusted using $\mathrm{HCl}$ and $\mathrm{NaOH}$. Ethylenediaminetetraacetic acid (EDTA) was used for EDTA titration method. Xylenol orange was used as indicator. Conductivity meter (Philips, PW-9527); FT-IR (IR200) were used.

\subsection{Sample Collection, Preparation and Carbonization}

ACROL was collected from Sabha City, Libya (Figure 1) and washed with distilled water to remove fines and dirt. The raw sample was dried at $40^{\circ} \mathrm{C}$ for $3 \mathrm{~h}$, crushed and sieved to a particle size with $90 \mu \mathrm{m}$ mesh and then was later immersed in diethyl ether for overnight until the solvents evaporated in order to remove the volatile oils. Then, it was placed in crucible and carbonized at $773 \mathrm{~K}$ for $1 \mathrm{~h}$. The carbon produced was allowed to cool to room temperature for overnight, sieved again with $90 \mu \mathrm{m}$, put in an air tight bottle and stored in desiccators [12].

\subsection{Characteristics of ACROAL}

The proximate composition of was determined according to Ofomaja et al., 2010 with slightly modifications [13]. The ACROL solution pH, conductivity, salinity, solubility and hydroscopic moisture content were determined using different method using American Society for Testing and Materials (ASTM) such as D3838-80, D4607-94, D2866-94 and D 2867-99.

\subsection{Batch Adsorption Studies}

The Optimization parameters for Adsorption of $\mathrm{Hg}(\mathrm{II})$ ions onto ACROL from Aqueous Solutions were reported previously by our group [12]. In order to determine the ACROL-Hg(II) adsorption isotherms, $40 \mathrm{mg}$ of ACROL was added to varied $\mathrm{Hg}$ (II) concentrations from 100 to $400 \mathrm{mg} / \mathrm{L} \mathrm{Hg(II)}$ at constant pH 2.4, $300 \mathrm{rpm}$ and $\mathrm{T}=$ 


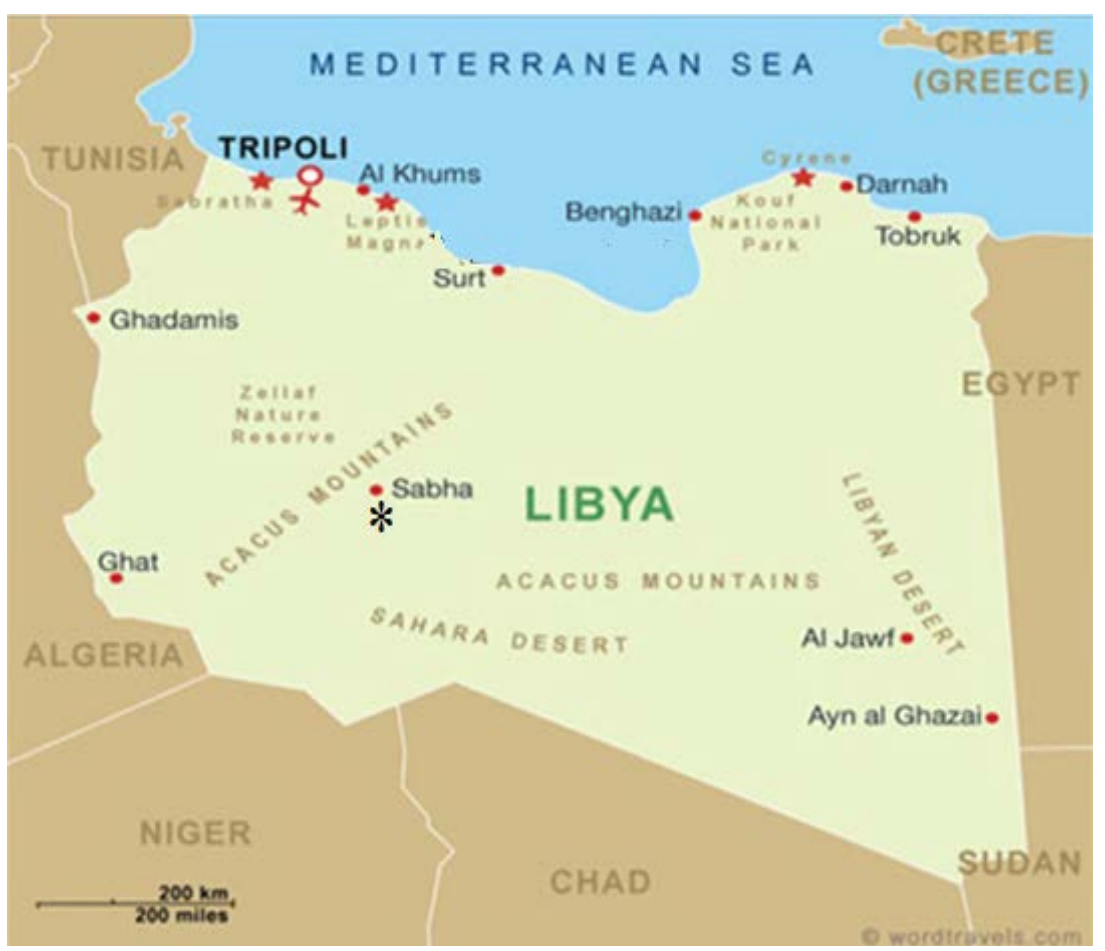

Figure 1. Rosmarinus officinalis leaves (ACROL samples site. *Sample site.

298, 308 and $318 \mathrm{~K}$. The ACROL-Hg(II) suspensions were placed on a stirring plate for 75 min to establish the equilibrium condition. Then, $10 \mathrm{ml}$ aliquots of the ACROL-Hg(II) suspensions were filtered using filter paper (Whatman No. P4). The residual Hg(II) concentration was determined by EDTA titration method using xylenol orange as indicator.

\subsection{Data Analysis}

Equation (1) is the percent of $\mathrm{Hg}(\mathrm{II})$ removal by ACROL and Equation (2) is amount of adsorption at equilibrium $\left(q_{e}, \mathrm{mg} / \mathrm{g}\right)$ :

$$
\begin{gathered}
\text { sorption } \%=\frac{C_{o}-C_{e}}{C_{o}} \times 100 \\
q_{e}=\left(\frac{C_{o}-C_{e}}{w}\right) v
\end{gathered}
$$

where: $C_{o}$ and $C_{e}=$ initial and equilibrium concentrations of $\mathrm{Hg}(\mathrm{II}) ; v=$ total volume; $w=$ weight of adsorbent. All the experiments were repeated for triplicate values.

\section{Results and Discussion}

\subsection{Characterization of Biosorbent}

Fourier transform infrared (FT-IR) spectroscopy was used to evaluate the functional groups on the surface of ACROL within the range of $600-4000 \mathrm{~cm}^{-1}$, as shown in Figure 2. FT-IR measurement for ACROL showed the presence of the following groups: O-H stretching (a broad peak at $3756.34 \mathrm{~cm}^{-1}$ ), C-H stretching (a weak peak at $\left.2925.87 \mathrm{~cm}^{-1}\right), \mathrm{C}=\mathrm{O}\left(1690.03 \mathrm{~cm}^{-1}\right), \mathrm{N}-\mathrm{H}\left(1416.90 \mathrm{~cm}^{-1}\right)$ and C-N $\left(1027.47 \mathrm{~cm}^{-1}\right)$ [13].

Physico-chemical characteristics of ACROL are shown in Table 1 . The characterization of ACROL as adsorbent is an important analysis to understand the behavior or mechanism of $\mathrm{Hg}(\mathrm{II})$ removal onto ACROL surface. Also, the extent of heavy metal adsorption onto biomass is influenced by the physico-chemical properties 


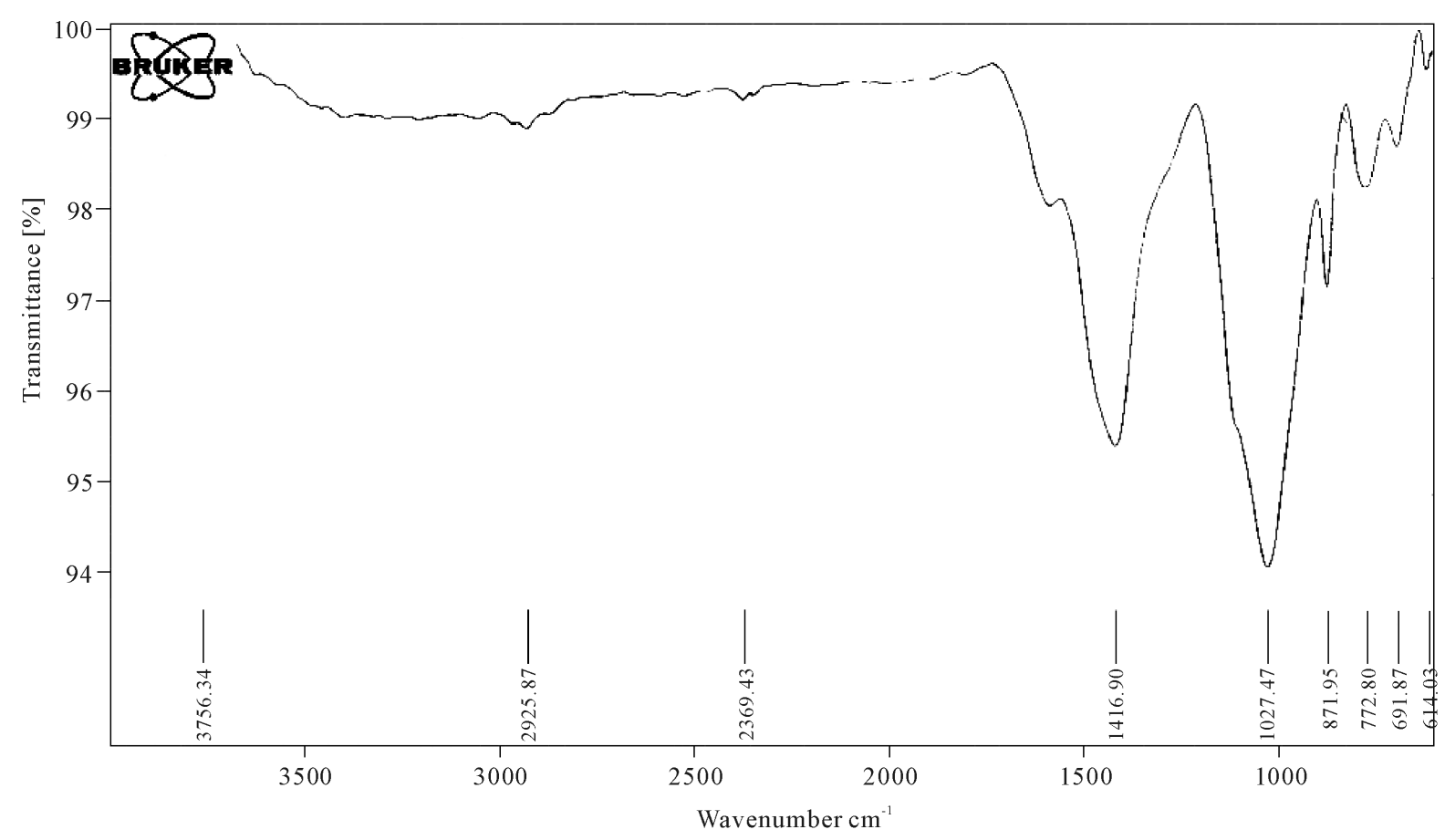

Figure 2. FTIR spectrum of ACROL.

Table 1. Physico-chemical characteristics of ACROL.

\begin{tabular}{cc}
\hline Physico-chemical properties & Results \\
\hline $\mathrm{pH}$ & 7.58 \\
Bulk density $\left(\mathrm{g} / \mathrm{cm}^{3}\right)$ & 0.40 \\
Moisture content (\%) & 1.33 \\
Solubility (\%) & 0.202 \\
Cellulose content (\%) & 65.0 \\
Conductivity ( $\mu \mathrm{s} / \mathrm{cm})$ & 489 \\
Salinity $(\mathrm{ppm})$ & 266 \\
\hline
\end{tabular}

of biomass [14]. The value of $\mathrm{pH} 7.58$ obtained in this research is useful for most applications. The moisture content tended to be was low of ACROL indicating that activated carbon of ACROL was properly prepared and handled. Bulk density of ACROL was relatively high comparing to other activated carbon. The higher bulk density is the better filterability of activated carbons and the lower limit of bulk density for activated carbon application is $0.25 \mathrm{~g} / \mathrm{cm}^{3}$. The conductivity and salinity values were noted to be higher than good conductivity for adsorption process ranged from 52 to $70 \mu \mathrm{s} / \mathrm{cm}$ [10]. This may be due to the presence of leachable ash as undesirable impurities and acid-water wash may not be able to reduced leachable ash.

\subsection{Adsorption Isotherm}

\subsubsection{Freundlich Isotherm}

The Freundlich isotherm is usually used for heterogeneous surface energy systems (non-uniform distribution of sorption heat) [15] [16]. Equation (3) is the Freundlich expression: 


$$
\log q_{e}=\log k_{F}+\frac{1}{n} \log C_{e}
$$

where: $K_{f}$ and $n$ are Freundlich constants, the $K_{f}$ is adsorption capacity while $n$ is biosorption intensity; $q_{e}=$ amount of $\mathrm{Hg}(\mathrm{II})$ per unit mass of adsorbate $(\mathrm{mg} / \mathrm{g}) ; C_{e}=$ equilibrium concentration $(\mathrm{mg} / \mathrm{L})$. The $q_{e}$ versus $C_{e}$ plot allows determining the Freundlich constants. The results of adsorption isotherm models are shown in Figure 3(a). The adsorption constants and the correlation coefficients are also listed in Table 2. According to Freundlich isotherm, the $1 / n$ values lie between 0 and 1 , this indicates favorable $\mathrm{Hg}$ (II) adsorption onto ACROL at low concentration and strong bond between Hg(II) and ACROL surface [17] [18]. Also, $n$ values have the same magnitude suggesting that the retention of $\mathrm{Hg}(\mathrm{II})$ ions from solution take place by ionic interactions in the first moment [19]. The Freundlich equation represents the best fit experimental data with $R^{2}=0.9818$ than other isotherm equations at low temperature.

\subsubsection{Langmuir Isotherm}

The Langmuir isotherm is usually used for a monolayer adsorption at specific homogenous sites on ACROL surface [16] [20]. Equation (4) is the Langmuir expression:

$$
\frac{C_{e}}{q_{e}}=\frac{1}{K_{L} q_{m}}+\frac{C_{e}}{q_{m}}
$$

where: $q_{m}=$ monolayer sorption capacity (mg/g) and $K_{L}=$ Langmuir equilibrium constant (L/g) [15]. A plot of $C_{e} / q_{e}$ versus $C_{e}$ yields a straight line, shown in Figure 3(b) and values are listed in Table 2. According to Langmuir model, $q_{m}$ values are increased with increasing temperature solution indicating that the $\mathrm{Hg}(\mathrm{II})$ ions is favorable adsorbed by ACROL at low temperature. However, $K_{L}$ values are decreased with increasing temperature of solution from 298 to $318 \mathrm{~K}$, therefore, less adsorption of $\mathrm{Hg}(\mathrm{II})$ onto the surface of ACROL would be
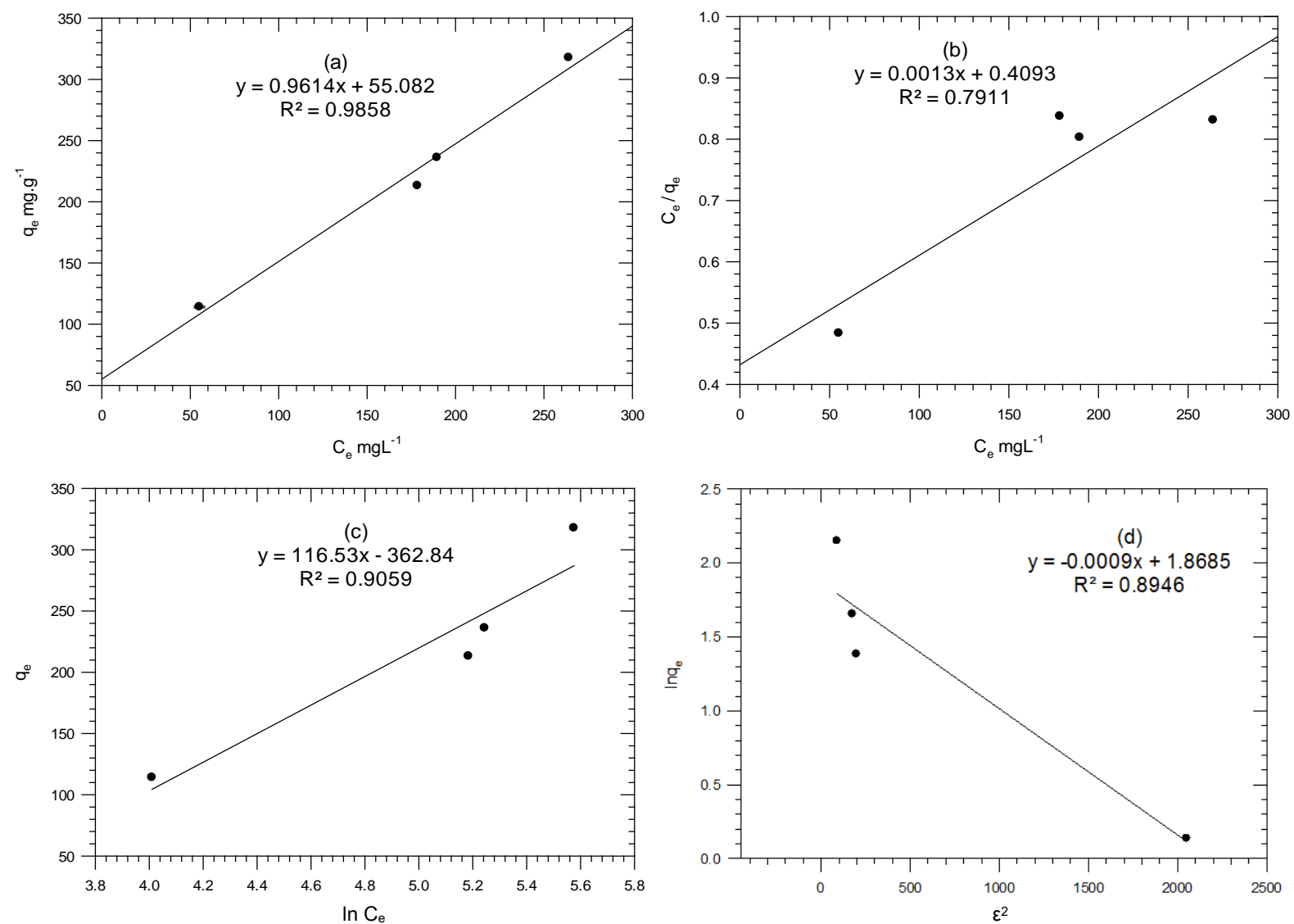

Figure 3. Plots for Freundlich (a), Langmiur (b), Temkin (c) and DRK (d) isotherms for Hg(II)-ACROL. 
Table 2. Adsorption isotherm constants of $\mathrm{Hg}(\mathrm{II})$ ions on ACROL.

\begin{tabular}{|c|c|c|c|c|c|c|c|c|c|}
\hline & \multirow{2}{*}{$T$} & & \multicolumn{3}{|c|}{ Freundlich constants } & \multicolumn{4}{|c|}{ Langmuir constants } \\
\hline & & & $K_{f}$ & $1 / n$ & $R^{2}$ & $K_{L}$ & $q_{m}$ & $R_{L}$ & $R^{2}$ \\
\hline & $\mathrm{K}$ & & $\mathrm{L} / \mathrm{g}$ & & & $\mathrm{L} / \mathrm{g}$ & $\mathrm{L} / \mathrm{mg}$ & Range & \\
\hline & 298 & & 0.5761 & 0.4518 & 0.9818 & 0.011 & 294.1 & $2.150-5.462$ & 0.9709 \\
\hline & 308 & & 0.9116 & 0.651 & 0.9723 & 0.005 & 454.6 & $1.516-3.004$ & 0.9767 \\
\hline & 318 & & 1.2555 & 0.7282 & 0.9286 & 0.004 & 588.2 & $1.418-2.619$ & 0.956 \\
\hline \multirow{2}{*}{$T$} & \multicolumn{5}{|c|}{ Temkin constants } & \multicolumn{4}{|c|}{ DRK constants } \\
\hline & & $K_{T}$ & $q_{m}$ & $B$ & $R^{2}$ & $B$ & $q_{m}$ & $E$ & $R^{2}$ \\
\hline $\mathrm{K}$ & & $\mathrm{J} / \mathrm{mol}$ & $\mathrm{L} / \mathrm{g}$ & & & $\mathrm{J} / \mathrm{mol}$ & $\mathrm{L} / \mathrm{g}$ & $\mathrm{J} / \mathrm{mol}$ & \\
\hline 298 & & 0.0772 & 74.98 & 35.26 & 0.9364 & 0.0003 & 220.1 & 40.83 & 0.8832 \\
\hline 308 & & 0.0393 & 114.2 & 23.15 & 0.8904 & 0.0005 & 254.3 & 31.62 & 0.8701 \\
\hline 318 & & 0.0351 & 143.4 & 18.44 & 0.8078 & 0.0005 & 291.6 & 31.62 & 0.8227 \\
\hline
\end{tabular}

$40 \mathrm{mg}$ of ACROL was added to $100 \mathrm{ml}$ of 100.8 , 263.8, 284.0 and $361.1 \mathrm{mg} / \mathrm{L}$ of $\mathrm{Hg}(\mathrm{II})$ at constant pH 2.4 , and $300 \mathrm{rpm}$. The suspensions were stirred for $75 \mathrm{~min}$.

expected at higher temperature. This indicates that the adsorption process is exothermic. On the other hand, the $K_{L}$ values were very slightly decreased with increasing temperature indicating that the adsorption of $\mathrm{Hg}(\mathrm{II})$ onto ACROL using Langmuir model cannot be evaluated using $K_{L}$. From $R^{2}$ of Freundlich and Langmuir models, the $\mathrm{Hg}(\mathrm{II})$ adsorption process onto ACROL was followed Freundlich at low temperature, while it was followed Langmuir models with increasing temperature indicating the desorption of $\mathrm{Hg}(\mathrm{II})$ multilayer onto ACROL was taken place with increasing temperature of solution. The $K_{L}$ was decreased with increasing temperature, indicating a bond strength between $\mathrm{Hg}(\mathrm{II})$ and ACROL decreased with increasing temperature and sorption is exothermic. Equation (5) is used to determine the constant separation factor, $R_{L}$ :

$$
R_{L}=\frac{1}{1+b C_{o}}
$$

The value of $R_{L}$ indicates the isotherm shape to be unfavorable $\left(R_{L}>1\right)$, favorable $\left(0<R_{L}<1\right)$ and irreversible $\left(R_{L}=1\right)$. The $R_{L}$ values were $>1$, which confirmed that the Hg(II) adsorption onto ACROL is unfavorable under these conditions using Langmuir isotherm for each temperature studied.

\subsubsection{Temkin Isotherm}

The Temkin isotherm is usually used for heterogeneous surface energy systems (non-uniform distribution of sorption heat) [15] [16].

$$
q_{e}=\frac{R T}{b} \ln A+\frac{R T}{b} \ln C_{e}
$$

where: $B=\frac{R T}{b}$ constant related to heat of sorption (J/mol) obtained From the Temkin plot $\left(q_{e}\right.$ versus $\left.\ln C_{e}\right) ; A$ (slope) $=$ Temkin isotherm equilibrium binding constant $(\mathrm{L} / \mathrm{g}) ; b$ (intercept $)=$ Temkin isotherm constant; $R=$ universal gas constant $\left(8.314 \mathrm{~J} \cdot \mathrm{mol}^{-1} \cdot \mathrm{K}^{-1}\right) T=$ Temperature at 298, 308 and $318 \mathrm{~K}$, shown in Figure 3(c) and listed in Table 2. The heat of $\mathrm{Hg}(\mathrm{II})$ adsorption $(b)$ is directly related to coverage of $\mathrm{Hg}(\mathrm{II})$ onto ACROL due to adsorbent-adsorbate interaction. It was decreased with increasing temperature from 35.26 to $18.44 \mathrm{~J} / \mathrm{mol}$, as listed in Table 2. This indicates that the heat of adsorption of $\mathrm{Hg}$ (II) onto the surface of ACROL decreases with increasing temperature from 298 to $318 \mathrm{~K}$ and the sorption is exothermic. Also, the $b$ values is higher than 80 $\mathrm{KJ} / \mathrm{mol}$ which indicating a chemical adsorption process and is a quite higher that reveals the strong ionic interaction between $\mathrm{Hg}(\mathrm{II})$ and ACROL [21]. $R^{2}$ is found to be the poorest fit of all experimental data. 


\subsubsection{Dubinin-Radushkevich (DRK) Isotherm}

DKR isotherm is used to determine the apparent energy of $\mathrm{Hg}(\mathrm{II})$ adsorption onto ACROL and has the linear form as following equation:

$$
\begin{aligned}
& \ln q_{e}=\ln q_{m}-\beta \varepsilon^{2} \\
& \varepsilon=R T \ln \left(1+\frac{1}{C_{e}}\right)
\end{aligned}
$$

where: $q_{m}$ is maximum sorption capacity (mg/g); $\beta$ is a activity coefficient constant related to sorption energy; $\varepsilon$ is Polanyi potential. The DKR parameters are calculated from the slop of the plot of $\ln q_{e}$ versus $\varepsilon^{2}$ gives $\beta$ $\left(\mathrm{mol}^{2} / \mathrm{J}^{2}\right)$ and exp (intercept) gives $q_{m}(\mathrm{mg} / \mathrm{g})$ in Figure 3(d) and listed in Table 2. The $\beta$ gives the mean free energy $(E)$ of sorption per molecule of the sorbate when it is transferred to the surface of the solid from infinity in the solution:

$$
E=\frac{1}{\sqrt{2 \beta}}
$$

The value of $E$ is $>8$ that reveals the sorption process follows chemical sorption, as listed in Table 2 .

\subsection{Adsorption Kinetics}

Two kinetic models were used to fit experimental data, Lagergren pseudo-first order Equation (9) and pseudosecond-order Equation (10):

$$
\begin{gathered}
\log \left(q_{e}-q_{t}\right)=\log q_{e}-\left(\frac{K_{1}}{2.303}\right) t \\
\frac{t}{q_{t}}=\frac{1}{k_{2} q_{2}^{2}}+\frac{t}{q_{2}} t
\end{gathered}
$$

where: $q_{e}$ is the adsorption equilibrium capacity (mg/g), $q_{t}$ is the amount of $\mathrm{Hg}(\mathrm{II})$ adsorbed (mg/g) at time $t, k_{1}$ is the rate constant of pseudo-first-order $\left(\mathrm{min}^{-1}\right), q_{2}$ is the maximum adsorption capacity $(\mathrm{mg} / \mathrm{g})$ and $k_{2}$ is the rate constant of pseudo-second-order (g/mg min) [16]. These parameters were obtained from slope and intercept of pseudo-first-order and pseudo-second-order plots between $\log \left(q_{e}-q_{t}\right)$ versus $t$ and $\left(t / q_{t}\right)$ versus $t$ [20]. Figure 4 shows pseudo-second-order plots for the $\mathrm{Hg}(\mathrm{II})$ adsorption onto ACROL surface and the kinetic parameters

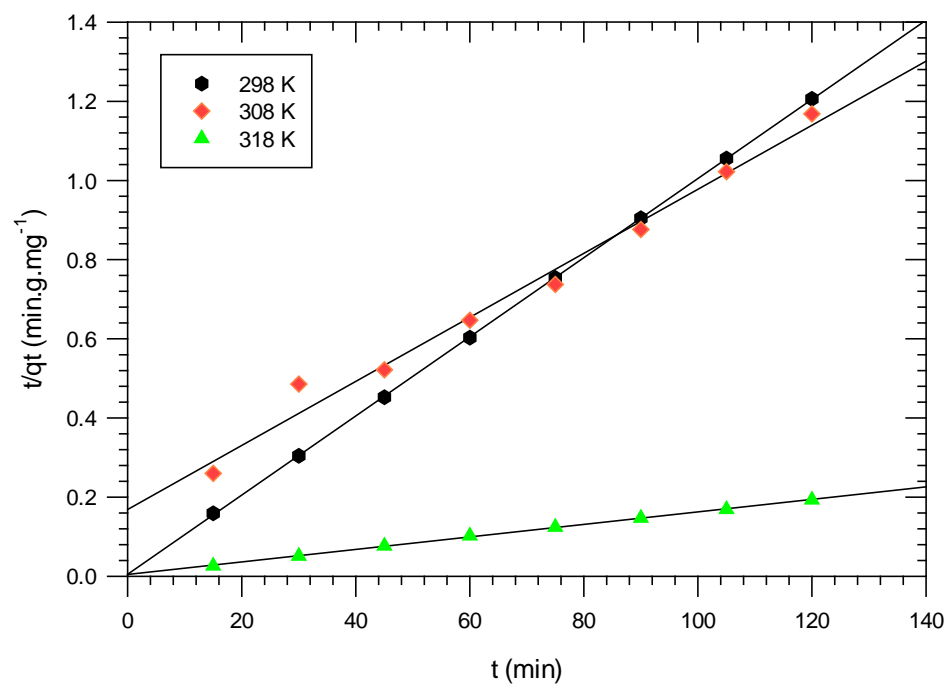

Figure 4. Pseudo-second order kinetic plots for the adsorption of $\mathrm{Hg}$ (II) onto ACROL at various temperatures. ACROL (40 mg) was added to 100 $\mathrm{ml}$ of $300 \mathrm{mg} / \mathrm{L} \mathrm{Hg}(\mathrm{II}), \mathrm{pH} 2.4$ and at 298, 308 and $318 \mathrm{~K}$. 
for tow models are presented in Table 3. From the values of $R^{2}$, the experimental data follow pseudo-secondorder kinetics comparatively better than pseudo-first-order. Also, Equation (10) is used to determine the best-fit for kinetic models by the square sum of errors (SSE) values:

$$
\mathrm{SSE}=\sum \frac{\left(q_{e(\exp )}-q_{e(\mathrm{cal})}\right)^{2}}{q_{e(\exp )}}
$$

The lowest value of SSE is the best model for the particular system. It is clear from SSE that pseudo-secondorder kinetic has lower SSE value than pseudo-first-order kinetic.

\subsection{Adsorption Thermodynamics}

Equation (11) is used to calculate the thermodynamic equilibrium constant $\left(K_{c}\right)$ for $\mathrm{Hg}(\mathrm{II})$-ACROL adsorption:

$$
K_{c}=\frac{C_{A e}}{C_{S e}}
$$

where: $C_{A e}$ : the equilibrium $\mathrm{Hg}(\mathrm{II})$ concentration adsorbed on ACROL at $(\mathrm{mg} / \mathrm{L})$ and $C_{S e}$ : the equilibrium $\mathrm{Hg}(\mathrm{II})$ concentration in solution $(\mathrm{mg} / \mathrm{L})$. The change in standard free energy $\left(\Delta G^{o}\right)$, enthalpy $\left(\Delta H^{\circ}\right)$ and entropy $\left(\Delta S^{o}\right)$ of adsorption were calculated from the following equation:

$$
\Delta G^{o}=-R T \ln K_{c}
$$

Thermodynamic parameters were estimated from van't Hoff. A plot of $\ln K_{c}$ versus $1 / T$ (see Figure 5) was used to determine $\Delta H^{o}$ (=-slope. $R$ ) and $\Delta S^{o}$ (= intercept. $R$ ) from slope and intercept by following equation:

$$
\ln K_{c}=\frac{-\Delta H^{o}}{R T}+\frac{\Delta S^{o}}{R}
$$

The calculated thermodynamic parameters are listed in Table 4. The negative values of $\Delta G^{o}$ at all temperature studied indicate the spontaneous nature of $\mathrm{Hg}(\mathrm{II})$ adsorption by ACROL. Also, the negative of $\Delta G^{o}$ values, less than $-15 \mathrm{~kJ} / \mathrm{mol}$, are connected with physical interactions between ACROL sites and $\mathrm{Hg}(\mathrm{II})$ ions. The experimental data show the adsorption capacities at equilibrium were decreased with an increase in temperature indicating that the adsorption process of $\mathrm{Hg}(\mathrm{II})$ onto ACROL follows exothermic path and the negative value of $\Delta H^{o}$ confirms the exothermic nature of $\mathrm{Hg}(\mathrm{II})$-ACROL adsorption process. These results confirm the previous findings which obtained in the adsorption isotherm study. Also, the negative values for both $\Delta H^{o}$ and $\Delta S^{o}$ suggest

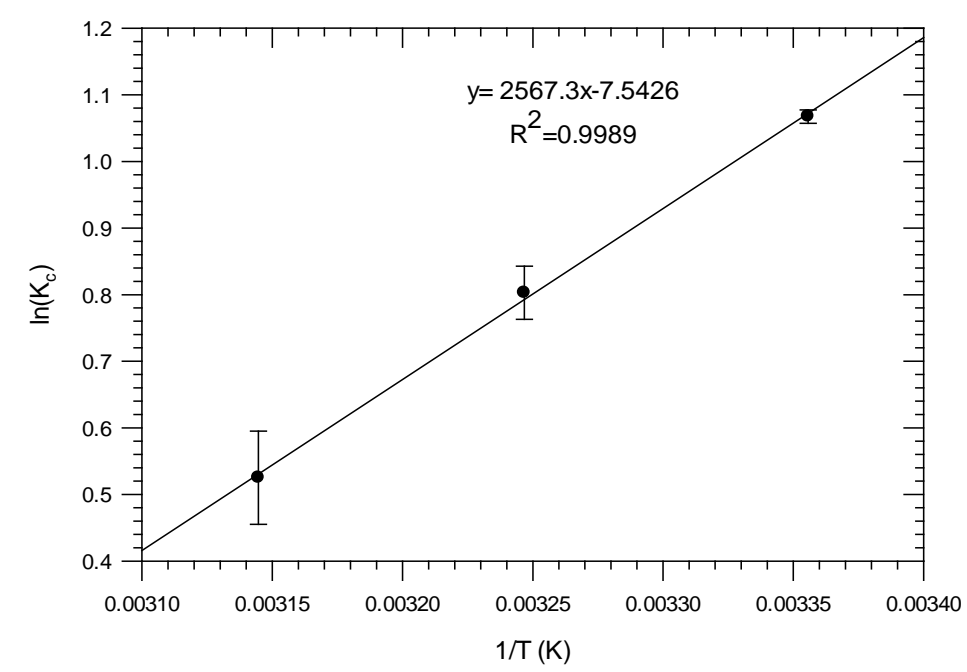

Figure 5. Relationship between Gibbs free energy calculated from different isotherm models and adsorption process temperature (K). $40 \mathrm{mg}$ of ACROL was added to varied $\mathrm{Hg}(\mathrm{II})$ concentrations from 100 to 400 $\mathrm{mg} / \mathrm{L} \mathrm{Hg(II)} \mathrm{at} \mathrm{constant} \mathrm{pH} \mathrm{2.4,} 200 \mathrm{rpm}$ and T = 298, 308 and $318 \mathrm{~K}$. 
Table 3. Kinetic parameters for $\mathrm{Hg}(\mathrm{II})$ adsorption by ACROL at various temperatures.

\begin{tabular}{|c|c|c|c|c|c|c|c|c|c|}
\hline \multirow[b]{2}{*}{$T(\mathrm{~K})$} & \multicolumn{5}{|c|}{ Pseudo-First order } & \multicolumn{4}{|c|}{ Pseudo-Second order kinetic } \\
\hline & $\begin{array}{c}q_{\text {eexp }} \\
(\mathrm{mg} / \mathrm{g})\end{array}$ & $\begin{array}{c}q_{e 1 c a l} \\
(\mathrm{mg} / \mathrm{g})\end{array}$ & $\begin{array}{c}k_{1} \times 10^{-2} \\
\left(\min ^{-1}\right)\end{array}$ & $R^{2}$ & SSE & $\begin{array}{c}q_{e 2 c a l} \\
(\mathrm{mg} / \mathrm{g})\end{array}$ & $\begin{array}{c}k_{2} \times 10^{-4} \\
(\mathrm{~g} / \mathrm{mg} \cdot \mathrm{min})\end{array}$ & $R^{2}$ & SSE \\
\hline 298 & 294.1 & 5.554 & 3.777 & 0.7502 & 283.1 & 100.0 & 200.0 & 1.000 & 128.1 \\
\hline 308 & 454.6 & 177.9 & 6.080 & 0.8543 & & 125.0 & 3.710 & 0.9711 & \\
\hline 318 & 588.2 & 13210 & 3.224 & 0.7536 & & 625.0 & 5.565 & 0.9992 & \\
\hline
\end{tabular}

ACROL (40 mg) was added to $100 \mathrm{ml}$ of $300 \mathrm{mg} / \mathrm{L}$ of $\mathrm{Hg}(\mathrm{II}), \mathrm{pH} 2.4$ and at 298, 308 and $318 \mathrm{~K}$.

Table 4. Thermodynamic parameters for sorption of $\mathrm{Hg}(\mathrm{II})$ on ACROL.

\begin{tabular}{ccccc}
\hline $\begin{array}{c}\text { Initial ion } \\
(\mathrm{mg} / \mathrm{L})\end{array}$ & $\Delta G^{o}(\mathrm{KJ} / \mathrm{mol})$ & $\Delta G^{o}(\mathrm{KJ} / \mathrm{mol})$ & $\Delta G^{o}(\mathrm{KJ} / \mathrm{mol})$ & $\begin{array}{c}\Delta H^{\circ} \\
(\mathrm{J} / \mathrm{mol})\end{array}$ \\
\hline 100.8 & $298 \mathrm{~K}$ & $308 \mathrm{~K}$ & $318 \mathrm{~K}$ & -308.8 \\
263.8 & -0.4694 & -0.8480 & -0.6080 & -0.9072 \\
284.0 & -2.322 & -2.142 & -2.001 & -1.594 \\
391.08 & -2.319 & -2.0967 & -1.389 \\
\hline
\end{tabular}

Optimum ACROL (40 mg) was added to $100 \mathrm{ml}$ of varied $\mathrm{Hg}(\mathrm{II})$ concentrations from $400 \mathrm{mg} / \mathrm{L} \mathrm{Hg(II)} \mathrm{at} \mathrm{different} \mathrm{temperature} \mathrm{(298,} 308$ and $318 \mathrm{~K}$ ) and at constant $\mathrm{pH} 2.4$ and $200 \mathrm{rpm}$ for $75 \mathrm{~min}$.

that the adsorption is physical in nature with a weak forces of attraction and a decrease in randomness at ACROL/Hg(II) interface during the adsorption process [16].

\section{Conclusion}

The findings in this research revealed that ACROL can be used as adsorbent for Hg(II) ions. The isotherm, kinetic and thermodynamic studies confirmed the experimental results. The equilibrium was the best described by Langmuir isotherm at high temperature, while the kinetic of the adsorption process was followed by pseudosecond-order model. The biosorption mechanism is chemisorption process. The negative values of $\Delta H^{o}$ and $\Delta S^{o}$ show that the $\mathrm{Hg}(\mathrm{II})$ adsorption process onto ACROL is exothermic in nature.

\section{References}

[1] Lu, X.C., Jiang, J.C., Sun, K., Wang, J.B. and Zhang, Y.P. (2014) Influence of the Pore Structure and Surface Chemical Properties of Activated Carbon on the Adsorption of Mercury from Aqueous Solutions. Marine Pollution Bulletin, 78, 69-76. http://dx.doi.org/10.1016/j.marpolbul.2013.11.007

[2] Luo, J.J., Hein, A.M. and Hwang, J.Y. (2004) Adsorption of Vapor Phase Mercury on Various Carbons. Journal of Minerals \& Materials Characterization \& Engineering, 3, 13-22.

[3] Wilcox, J., Rupp, E., Ying, S.C., Lim, D.-H., Negreira, A.S., Kirchofer, A., Feng, F. and Lee, K. (2012) Mercury Adsorption and Oxidation in Coal Combustion and Gasification Processes. International Journal of Coal Geology, 90-91, 4-20.

[4] Ariya, P.A., et al. (2004) The Arctic: A Sink for Mercury. Tellus B, 56, 397-403. http://dx.doi.org/10.1111/j.1600-0889.2004.00118.x

[5] Malamisa, S. and Katsoua, E. (2013) A Review on Zinc and Nickel Adsorption on Natural and Modified Zeolite, Bentonite and Vermiculite: Examination of Process Parameters, Kinetics and Isotherms. Journal of Hazardous Materials, 252-253, 428-461.

[6] Clercq, J.D. (2012) Removal of Mercury from Aqueous Solutions by Adsorption on a New Ultra Stable Mesoporous Adsorbent and on a Commercial Ion Exchange Resin. International Journal of Industrial Chemistry, 1, 3.

[7] Erhayem, M. and Sohn, M. (2014) Stability Studies for Titanium Dioxide Nanoparticles upon Adsorption of Suwannee River Humic and Fulvic Acids and Natural Organic Matter. Science of the Total Environment, 468-469, 249-257. http://dx.doi.org/10.1016/j.scitotenv.2013.08.038 
[8] Evbuomwan, B.O., Agbede, A.M. and Atuka, M.M. (2013) A Comparative Study of the Physico-Chemical Properties of Activated Carbon from Oil Palm Waste (Kernel Shell and Fibre). International Journal of Science and Engineering Investigations, 2, 75-79.

[9] Madu, P.C. and Lajide, L. (2013) Physicochemical Characteristics of Activated Charcoal Derived from Melon Seed Husk. Journal of Chemical and Pharmaceutical Research, 5, 94-98.

[10] Verla, A.W., Horsfall Jr., M., Verla, E.N., Spiff, A.I. and Ekpete, O.A. (2012) Preparation and Characterization of Activated Carbon from Fluted Pumpkin (Telfairia Occidentalis Hook.F) Seed Shell. Asian Journal of Natural \& Applied Science, 1, 39-50.

[11] Aziza, K.G., Haiko, H., Artur, S.J., Simone, M.S. (2008) Rosemary (Rosmarinus officinalis)—A Study of the Composition, Antioxidant and Antimicrobial Activities of Extracts Obtained with Supercritical Carbon Dioxide. Food Science and Technology (Campinas), 28, 463-469. http://dx.doi.org/10.1590/S0101-20612008000200030

[12] Al-Tohami, F., Erhayem, M., Ali, R. and Ali, M. (2014) Optimization Parameters for Adsorption of Hg (II) Ions onto Carbonized Rosmarinus Officinalis Leaves (ACROL) from Aqueous Solutions. TCSSE International Conference of Science and Technology, Dubai, 26-27 August 2014. (As Poster)

[13] Ofomaja, A.E. (2010) Equilibrium Studies of Copper Ion Adsorption onto Palm Kernel Fibre. Journal of Environmental Management, 91, 1491-1499. http://dx.doi.org/10.1016/j.jenvman.2010.02.029

[14] Memon, G.Z., Bhanger, M.I. and Akhtar, M. (2007) The Removal Efficiency of Chestnut Shells for Selected Pesticides from Aqueous Solutions. Journal of Colloid and Interface Science, 315, 33-40. http://dx.doi.org/10.1016/j.jcis.2007.06.037

[15] Mohamed, A., Hesham, G.I. and Mohamed, M.A. (2008) Equilibrium and Kinetics of Chromium Adsorption on Cement Kiln Dust. Proceedings of the World Congress on Engineering and Computer Science, San Francisco, 22-24 October 2008, 54-62.

[16] Atar, N., Olgun, A. and Wangb, S. (2012) Adsorption of Cadmium (II) and Zinc (II) on Boron Enrichment Process Waste in Aqueous Solutions: Batch and Fixed-Bed System Studies. Chemical Engineering Journal, 192, 1-7. http://dx.doi.org/10.1016/j.cej.2012.03.067

[17] Erhayem, M. and Sohn, M. (2014) Effect of Humic Acid Source on Humic Acid Adsorption onto Titanium Dioxide Nanoparticles. Science of the Total Environment, 470-471, 92-98. http://dx.doi.org/10.1016/j.scitotenv.2013.09.063

[18] Varank, G., Demir, A., Yetilmezsoy, K., Top, S., Sekman, E. and Bilgili, M.S. (2012) Removal of 4-Nitrophenol from Aqueous Solution by Natural Low-Cost Adsorbents. Indian Journal of Chemical Technology, 19, 7-25.

[19] Bulgariu, L., Rățoi, M., Bulgariu, D. and Macoveanu, M. (2008) Equilirium Study of Pb (II) and Hg (II) Sorption from Aqueous Solutions by Moss Peat. Bulgariu, Laura, Mioara Rățoi, Dumitru Bulgariu, and Matei Macoveanu. EQUIL Environmental Engineering \& Management Journal, 7, 511-516.

[20] Nagy, B., Maica, A., Indolean, C. and Burca, S. (2013) Cadmium (II) Ions Removal from Aqueous Solutions Using Romanian Untreated fir Tree Sawdust a Green Biosorbent. Acta Chimica Slovenica, 60, 263-273.

[21] Shahmohammadi-Kalalagh, S., Babazadeh, H., Nazemi, A. and Manshouri, M. (2011) Isotherm and Kinetic Studies on Adsorption of $\mathrm{Pb}, \mathrm{Zn}$ and $\mathrm{Cu}$ by Kaolinite. Caspian Journal of Environmental Sciences, 9, 243-255. 
Scientific Research Publishing (SCIRP) is one of the largest Open Access journal publishers. It is currently publishing more than 200 open access, online, peer-reviewed journals covering a wide range of academic disciplines. SCIRP serves the worldwide academic communities and contributes to the progress and application of science with its publication.

Other selected journals from SCIRP are listed as below. Submit your manuscript to us via either submit@scirp.org or Online Submission Portal.
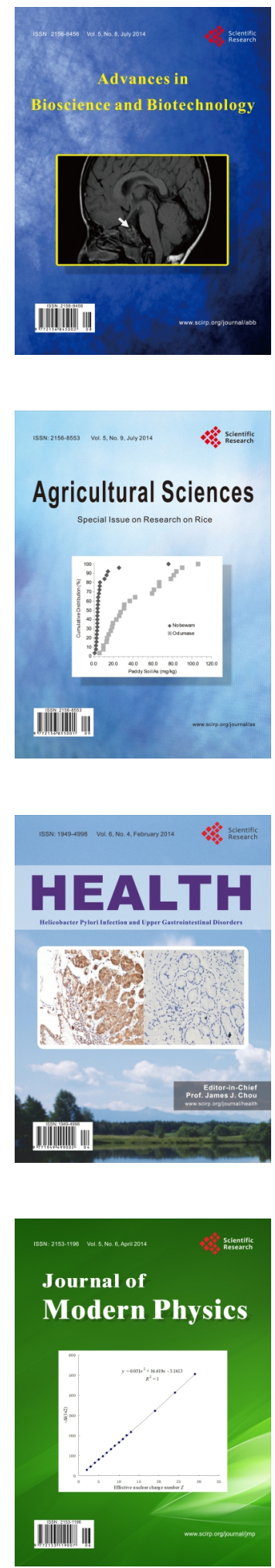
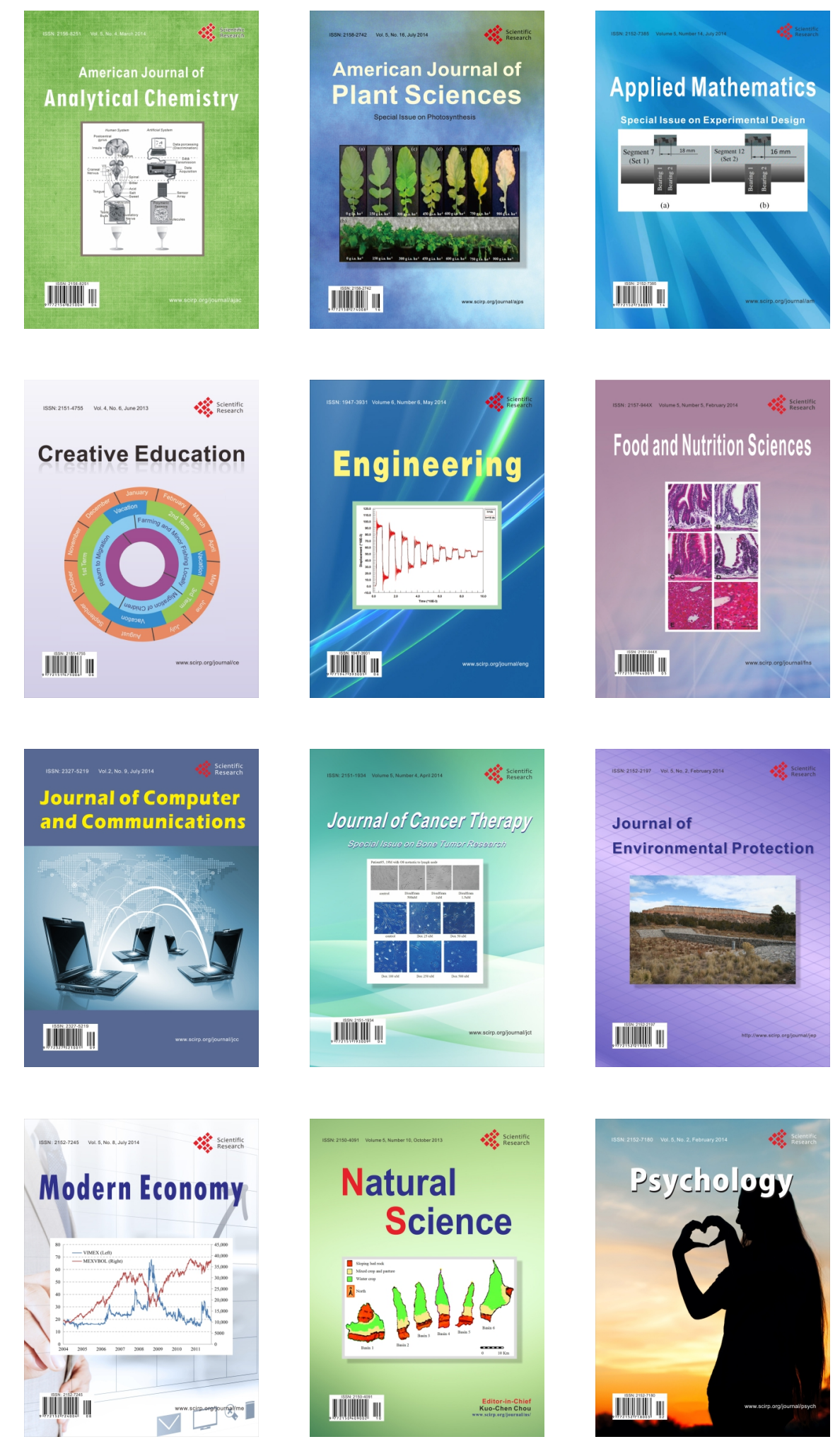